\title{
Decomposition of hydrogen peroxide in alkaline cyanide solutions
}

\author{
by T. Fungene*, D.R. Groot*†, T. Mahlangu ${ }^{\ddagger}$, and K.C. Sole*
}

\section{Synopsis}

Although oxygen is widely employed as the oxidant of choice in gold leaching by cyanide, its low aqueous solubility presents some drawbacks in practical application; hydrogen peroxide has therefore been considered as a possible alternative. The aim of this investigation was to study the catalytic decomposition of hydrogen peroxide, which generates an oxidizing intermediate species, and to understand its effect on cyanide destruction. Operating conditions that facilitated the effective decomposition of hydrogen peroxide were established by varying the $\mathrm{pH}$ and catalyst type and concentration. The oxidizing intermediate, detected using an indirect technique, was found to be the hydroxyl radical $\left(\mathrm{OH}^{\circ}\right)$. $\mathrm{OH}^{\prime}$ is commonly generated in acidic solutions, but this work demonstrated that it is also produced at the alkaline $\mathrm{pH}$ values necessary for cyanide gold leaching. The effects of free and complexed iron and copper catalysts on the oxidation and consumption of hydrogen peroxide and cyanide were also investigated. It was shown that the cyano complexes of Fe(II) and $\mathrm{Cu}(\mathrm{I})$ are also effective as decomposition catalysts. Hydrogen peroxide concentrations above $0.01 \mathrm{M}$ decreased the free cyanide concentration, which was attributed to the probable formation of the cyanate anion (CNO-). Although cyanide consumption increased due to its oxidation in the presence of $\mathrm{OH}$, excessive cyanide consumption in the presence of copper was attributed primarily to its complexation by the unstable copper(I) cyanide species. Rate constants for the decompositions of $\mathrm{H}_{2} \mathrm{O}_{2}$ and cyanide by ferrocyanide and copper cyanide were calculated; the latter was identified as being a better catalyst.

Keywords

hydrogen peroxide, decomposition, Fenton chemistry, cyanide, gold leaching, radical.
Loroesch, 1990), the maximum aqueous solubility of dissolved oxygen is about $20 \mathrm{mg} / \mathrm{L}$ (Loroesch, 1990). To overcome this limitation of oxygen mass transfer, the application of a liquid oxidant, such as hydrogen peroxide $\left(\mathrm{H}_{2} \mathrm{O}_{2}\right)$, has been proposed (Ball et al., 1989; Knorre et al., 1993, 1994). Use of $\mathrm{H}_{2} \mathrm{O}_{2}$ in the cyanide leaching of gold has the potential to ensure the fast and homogenous distribution of an active oxygen species in the pulp. Peroxide-assisted leaching has been acknowledged to exhibit enhanced kinetics and improved gold recoveries compared with both conventional and improved aeration techniques (Arslan et al., 2003; Guzman et al., 1999; Loroesch, 1990); however, these advantages need to be weighed against the increased cyanide consumption due to its loss by oxidation by $\mathrm{H}_{2} \mathrm{O}_{2}$.

When $\mathrm{H}_{2} \mathrm{O}_{2}$ is added to an aqueous system, the resulting decomposition produces dissolved oxygen that is directly available for leaching:

$$
2 \mathrm{H}_{2} \mathrm{O}_{2} \rightarrow 2 \mathrm{H}_{2} \mathrm{O}+\mathrm{O}_{2}
$$

This decomposition is well known to be catalysed by metallic species, specifically iron and copper, in what are termed Fenton and Fenton-like reactions, respectively (Fenton, 1894; Haber and Weiss, 1934; Watts and Teel, 2005). H.J.H. Fenton discovered in 1894 that several metals exhibit a strong catalytic effect that generates highly reactive hydroxyl radicals; these impart oxygen transfer properties that improve the use of hydrogen peroxide. Iron and copper commonly occur as impurities in gold ores (usually as sulphides), so leaching can benefit from the enhanced

* Department of Materials Science and Metallurgical Engineering, University of Pretoria, South Africa.

+ Department of Mining and Process Engineering, Namibia University of Science and Technology, Windhoek, Namibia.

\& Randgold Resources, Johannesburg, South Africa.

(C) The Southern African Institute of Mining and Metallurgy, 2018. ISSN 2225-6253. Paper received Nov. 2017; revised paper received Mar. 2018. 


\section{Decomposition of hydrogen peroxide in alkaline cyanide solutions}

dissolved oxygen content resulting from the catalytic dissociation of $\mathrm{H}_{2} \mathrm{O}_{2}$ into free oxygen and water. However, if the $\mathrm{pH}$ is too high, iron will precipitate as $\mathrm{Fe}(\mathrm{OH})_{3}$ and $\mathrm{H}_{2} \mathrm{O}_{2}$ will decompose to oxygen.

Debate regarding the reaction pathway for the decomposition of $\mathrm{H}_{2} \mathrm{O}_{2}$, specifically concerning the nature of the oxidizing intermediate(s), is ongoing (Barbusiński, 2009). Two main pathways are postulated: one considers hydroxyl radical ( $\left.\mathrm{OH}^{\prime}\right)$ formation (Barbusiński, 2009; Deguillaume et al., 2005; Haber and Weiss, 1932, 1934); the other is a non-radical pathway that considers ferryl ion $\left(\mathrm{FeO}^{2+}\right)$ formation (Barbusiński, 2009; Bray and Gorin, 1932). The respective reactions are shown in Equations [3] and [4]:

$$
\begin{aligned}
& \mathrm{Fe}^{2+}+\mathrm{H}_{2} \mathrm{O}_{2} \rightarrow \mathrm{Fe}^{3+}+\mathrm{OH}^{-}+\mathrm{OH}^{-} \\
& \mathrm{Fe}^{2+}+\mathrm{H}_{2} \mathrm{O}_{2} \rightarrow \mathrm{FeO}^{2+}+\mathrm{H}_{2} \mathrm{O}
\end{aligned}
$$

An aim of this work was to determine the pathway for the decomposition of $\mathrm{H}_{2} \mathrm{O}_{2}$, i.e., to identify whether a radical is involved in the reaction, specifically in alkaline cyanide solutions. This could lead to a better understanding of the mechanism by which dissolved oxygen levels are improved by the addition of $\mathrm{H}_{2} \mathrm{O}_{2}$ and its effects on other possible consumers of cyanide $\left(\mathrm{CN}^{-}\right)$in gold leaching.

The study comprised four main parts: determination of the effects of $\mathrm{pH}$ and catalyst type and concentration on the decomposition of $\mathrm{H}_{2} \mathrm{O}_{2}$; the effect of $\mathrm{H}_{2} \mathrm{O}_{2}$ concentration on the decomposition of cyanide; examination of Fenton and Fenton-like reactions in the presence of cyanide; and detection of the presence of radicals in acidic and alkaline solutions.

\section{Experimental}

\section{Reagents}

Hydrogen peroxide (30\%) was employed as received. Copper and iron, employed as the decomposition catalysts, were added as the respective sulphate salts for experiments in the absence of cyanide and as $\mathrm{K}_{4} \mathrm{Fe}(\mathrm{CN})_{6}$ and $\mathrm{CuCN}$ for those in the presence of cyanide. Cyanide was also provided as $\mathrm{NaCN}$ in some experiments. Concentrated (98\%) $\mathrm{H}_{2} \mathrm{SO}_{4}$ and $\mathrm{CaO}$ were employed for $\mathrm{pH}$ adjustment. All chemicals were of analytical reagent grade, supplied by Merck and Sigma Aldrich.

\section{Methods}

\section{Effect of $\mathrm{pH}$ and catalyst concentration on the decomposition of $\mathrm{H}_{2} \mathrm{O}_{2}$}

The experiments for each catalyst were carried out at both acidic (the natural $\mathrm{pH}$ of the catalyst, defined as the resulting $\mathrm{pH}$ when the metal salt was added to water: $\mathrm{pH} 2-3$ for iron; $\mathrm{pH} 3-4$ for copper) and alkaline conditions ( $\mathrm{pH} \mathrm{9-10}$ obtained by addition of $\mathrm{CaO}$ ). Sixty millilitres (mL) of $\mathrm{H}_{2} \mathrm{O}_{2}$ $(0.6 \mathrm{M})$ and $0.5 \mathrm{~g} / \mathrm{L}$ (approx. $0.01 \mathrm{M}$ ) of iron or copper, obtained by addition of the respective sulphate salt, were added to deionized water to make up a volume of $1000 \mathrm{~mL}$. The solutions were magnetically stirred at a constant speed of $500 \mathrm{r} / \mathrm{min}$. Individual experiments were carried out at $\mathrm{pH}$ values ranging from 4 to 11 . After 15 minutes at each $\mathrm{pH}$, a $10 \mathrm{~mL}$ aliquot was analysed for residual $\mathrm{H}_{2} \mathrm{O}_{2}$ concentration.
To study the effect of catalyst concentration, experiments were carried out using an initial metal catalyst concentration of $0.1 \mathrm{~g} / \mathrm{L}$ (approx. $0.002 \mathrm{M}$ ). This was increased stepwise to $3 \mathrm{~g} / \mathrm{L}$ (approx. $0.06 \mathrm{M}$ ) after equilibration for 15 minutes. After equilibration, the dissolved oxygen (DO) content, redox potential $\left(E_{h}\right)$ (reported relative to the $\mathrm{Ag} / \mathrm{AgCl}$ reference electrode, $E^{O}=0.222 \mathrm{~V}$ ), and $\mathrm{H}_{2} \mathrm{O}_{2}$ content of each solution were measured.

\section{Effect of $\mathrm{H}_{2} \mathrm{O}_{2}$ concentration on the decomposition of cyanide}

The effect of $\mathrm{H}_{2} \mathrm{O}_{2}$ concentration on cyanide decomposition in the absence of a metal catalyst was determined using 1000 $\mathrm{mL}$ of $0.015 \mathrm{M} \mathrm{NaCN}$ and initial $\mathrm{H}_{2} \mathrm{O}_{2}$ concentrations ranging from $0.005 \mathrm{M}$ to $0.1 \mathrm{M}$. CaO was added to maintain a $\mathrm{pH}$ of 10-11.5 throughout each test. Samples taken after selected reaction times were analysed for $\mathrm{pH}$ and cyanide content.

\section{Effect of iron and copper (free and complexed) on the decomposition of $\mathrm{H}_{2} \mathrm{O}_{2}$ and cyanide}

The effects of iron and copper (as both free and complexed ions) on $\mathrm{H}_{2} \mathrm{O}_{2}$ decomposition were investigated to determine whether $\mathrm{H}_{2} \mathrm{O}_{2}$ would decompose similarly in both Fenton and Fenton-like reactions. The metals were added both as sulphates $\left(\mathrm{FeSO}_{4} \cdot 7 \mathrm{H}_{2} \mathrm{O} ; \mathrm{CuSO}_{4} \cdot 5 \mathrm{H}_{2} \mathrm{O}\right)$ and as cyanide complexes $\left(\mathrm{K}_{4} \mathrm{Fe}(\mathrm{CN})_{6} ; \mathrm{CuCN}\right)$ at a concentration of $0.004 \mathrm{M}$ to a solution of $0.01 \mathrm{M} \mathrm{H}_{2} \mathrm{O}_{2}$. The $\mathrm{pH}$ was maintained in the range 10-11.5.

Determination of the effects of iron and copper cyanide complexes on the aqueous free cyanide concentration followed the same experimental procedure as described above, with $0.01 \mathrm{M}$ free cyanide added as NaCN. The tests were carried out with and without the addition of $0.01 \mathrm{M}$ $\mathrm{H}_{2} \mathrm{O}_{2}$. Samples taken at selected reaction times were analysed for $\mathrm{pH}, \mathrm{H}_{2} \mathrm{O}_{2}$, and cyanide content.

\section{Radical detection studies}

An indirect method for identifying the presence of the hydroxyl radical was employed, based on analysis of the products of the reaction between salicylic acid and $\mathrm{OH}^{\text {: }}$. Detection of the 2,3- or 2,5-dihydroxybenzoic acid (DHBA) isomers (Equation [5]) confirms the presence of $\mathrm{OH}$ (Nguyen et al., 2008). Fenton reactions were carried out in the presence of sufficient salicylic acid to react with the free $\mathrm{OH}^{\prime}$ generated. To a $1 \mathrm{~L}$ solution of specified $\mathrm{pH}$ (acidic or alkaline), $0.01 \mathrm{M} \mathrm{Fe}^{2+}$ was added, followed by $0.5 \mathrm{M} \mathrm{H}_{2} \mathrm{O}_{2}$ and $0.12 \mathrm{M}$ salicylic acid (stoichiometric excess of $20 \%$ with respect to $\mathrm{Fe}^{2+}$ ). The solution was allowed to react for 1 hour at $30^{\circ} \mathrm{C}$ and then cooled to room temperature, after which it was poured into a separating funnel and intimately mixed with diethyl ether to extract only the desired organic products (2,3- and/or 2,5-DHBA). The organic phase was evaporated over low heat, leaving a solid that was collected for identification by infrared (IR) and nuclear magnetic resonance (NMR) spectroscopy.

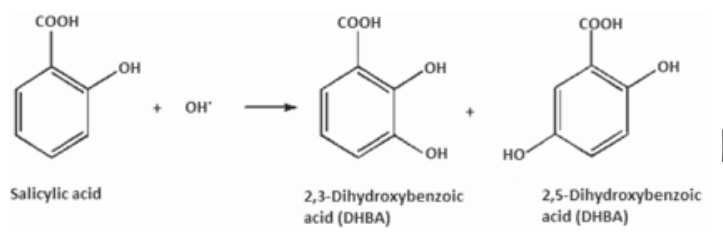




\section{Decomposition of hydrogen peroxide in alkaline cyanide solutions}

\section{Analytical methods}

$\mathrm{H}_{2} \mathrm{O}_{2}$ concentrations were titrimetrically determined using $0.025 \mathrm{M} \mathrm{KMnO}_{4}$ (Klassen et al.,1994). Free cyanide $\left(\mathrm{CN}^{-}\right.$) was determined by titration with $0.1 \mathrm{M} \mathrm{AgNO}_{3}$, using Rhodamine B as the indicator (Mendham et al., 2000). DO content was measured using a dissolved oxygen meter (model 5100 OUR/SOUR, YSI, USA); pH and $\mathrm{E}_{\mathrm{h}}$ were measured using a combination meter (model 704, Metrohm, Switzerland). All tests were repeated twice, giving a total of three replicates to establish the measure of uncertainty, indicated by the error bars on the graphs in Figures 1 to 9 .

\section{Results and discussion}

\section{Effect of $\mathrm{pH}$ on decomposition of hydrogen peroxide}

Figure 1 shows the effect of equilibrium $\mathrm{pH}$ on the extent of decomposition of $\mathrm{H}_{2} \mathrm{O}_{2}$ in the presence of $0.01 \mathrm{M}$ iron or copper. It is evident that, for both metals, an increase in $\mathrm{pH}$ increased the extent of decomposition. This result is in agreement with those of Nicoll and Smith (1955), who observed that the decomposition of $\mathrm{H}_{2} \mathrm{O}_{2}$ in distilled water in the presence of a catalytic impurity increased as the alkalinity of the solution increased. The effective decomposition at high $\mathrm{pH}$ values accounts for the reported efficiency of $\mathrm{H}_{2} \mathrm{O}_{2}$ as an oxidant in alkaline gold leaching (Guzman et al., 1999). It is also evident that copper resulted in more effective decomposition of $\mathrm{H}_{2} \mathrm{O}_{2}$ above $\mathrm{pH} 7$, indicating that it is a better catalyst than iron in the alkaline $\mathrm{pH}$ range.

\section{Effect of catalyst concentration on decomposition of $\mathrm{H}_{2} \mathrm{O}_{2}$ in acidic and alkaline solutions}

Figures 2 and 3 compare the effects of increasing iron or copper catalyst concentration on the Eh and DO due to $\mathrm{H}_{2} \mathrm{O}_{2}$ decomposition in acidic (natural $\mathrm{pH}$ for each catalyst) and alkaline ( $\mathrm{pH}$ 9-10) ranges.

Figure 2 shows that the solution potential gradually increased at acidic $\mathrm{pH}$ values for increased iron concentrations because the ferrous iron concentration decreased as a result of oxidation to ferric ions in the presence of $\mathrm{H}_{2} \mathrm{O}_{2}$ :

$$
\mathrm{Fe}^{2+}+\mathrm{H}_{2} \mathrm{O}_{2} \rightarrow \mathrm{Fe}^{3}++\mathrm{OH}^{-}+\mathrm{OH}^{-}
$$

This effect was not evident for $\mathrm{Cu}^{2+}$, which is stable in the divalent form under these conditions. In contrast, a decrease in $E_{h}$ was observed in alkaline solutions for both metals. This is attributed to the formation of stable hydroxide

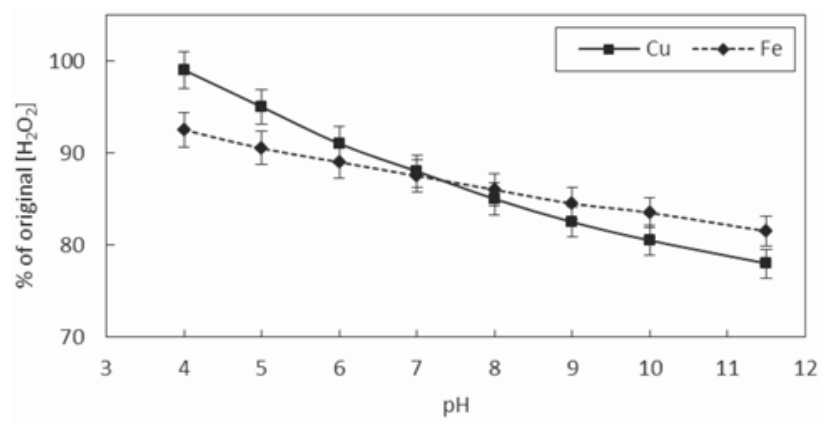

Figure 1-Extent of $\mathrm{H}_{2} \mathrm{O}_{2}$ decomposition as a function of $\mathrm{pH}$ in the presence of iron and copper. (Initial $\left[\mathrm{H}_{2} \mathrm{O}_{2}\right]$ : $0.6 \mathrm{M}$; initial [M2+]: $0.01 \mathrm{M}$; initial pH for Fe test: 2-3; initial pH for Cu test: 3-4) species of both iron and copper under these conditions. These species are known to be active catalysts in the decomposition of $\mathrm{H}_{2} \mathrm{O}_{2}$ (Lin and Gurol, 1998). At alkaline $\mathrm{pH}$, heavy metal ions (such as iron or copper) form unstable peroxides, causing decomposition of $\mathrm{H}_{2} \mathrm{O}_{2}$; in addition, colloidal hydroxides are formed as the $\mathrm{pH}$ increases. These metal hydroxides are considered to be more active catalysts for $\mathrm{H}_{2} \mathrm{O}_{2}$ decomposition than the free or complexed metal ions (Lin and Gurol, 1998; Nicoll and Smith, 1955). It is notable that both catalysts had the most significant effect at a concentration of $0.5 \mathrm{~g} / \mathrm{L}$; above this concentration, further improvements in performance were limited.

As shown in Figure 3, the DO content was higher in alkaline solutions for catalyst concentrations above $0.5 \mathrm{~g} / \mathrm{L}$, which indicates greater extents of decomposition of $\mathrm{H}_{2} \mathrm{O}_{2}$ (see Equation [2]). This confirmed that such stable hydroxides tend to be better catalysts than their respective free transition-metal cations (Lin and Gurol, 1998; Nicoll and Smith, 1955). It is also notable that the DO concentrations reached close to $50 \mathrm{mg} / \mathrm{L}$ under these conditions, which is considerably higher than the equilibrium oxygen concentration reported when using enhanced aeration with gaseous oxygen (approx. $20 \mathrm{mg} / \mathrm{L}$ ) (Loroesch, 1990).

\section{Effect of $\mathrm{H}_{2} \mathrm{O}_{2}$ concentration on rate of decomposition of cyanide}

The use of $\mathrm{H}_{2} \mathrm{O}_{2}$ in treating wastewaters containing cyanide and/or cyanide complexes is common practice (Ozcan et al.,

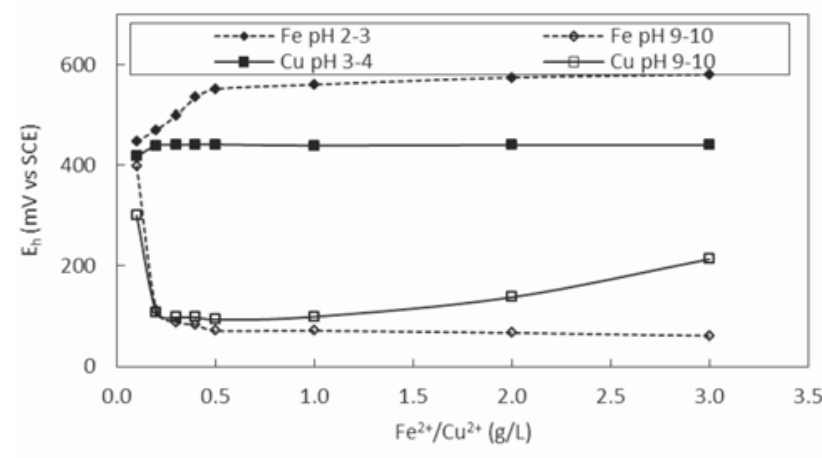

Figure 2-Solution redox potential as a function of $\mathrm{Fe}^{2+}$ and $\mathrm{Cu}^{2+}$ catalyst concentration in acidic and alkaline solutions. (Initial $\left[\mathrm{H}_{2} \mathrm{O}_{2}\right]$ : $0.6 \mathrm{M})$

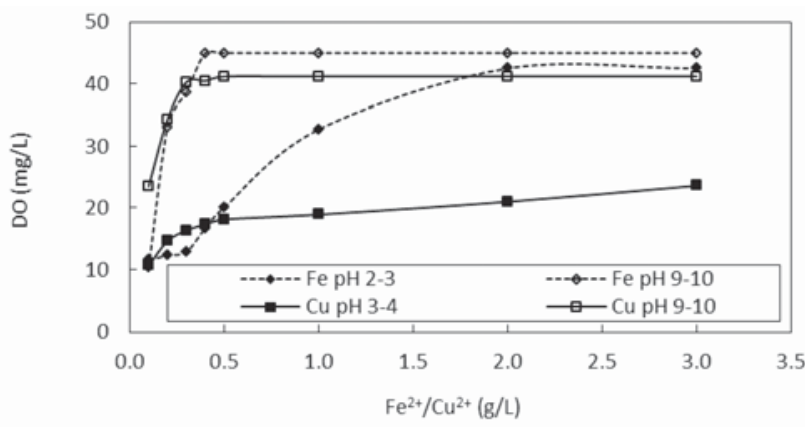

Figure 3-Dissolved oxygen concentration as a function of $\mathrm{Fe}^{2+}$ and $\mathrm{Cu}^{2}+$ catalyst concentration in acidic and alkaline solutions. (Initial $\left[\mathrm{H}_{2} \mathrm{O}_{2}\right]$ : $0.6 \mathrm{M}$ ) 


\section{Decomposition of hydrogen peroxide in alkaline cyanide solutions}

2011). This ability of $\mathrm{H}_{2} \mathrm{O}_{2}$ to destroy cyanide potentially mitigates against its use in cyanide leaching systems. Figure 4 shows the effect of $\mathrm{H}_{2} \mathrm{O}_{2}$ concentrations ranging from $0.005 \mathrm{M}$ to $0.10 \mathrm{M}$ on the rate of decomposition of free cyanide. A significant decrease in $\mathrm{CN}^{-}$concentration was observed for $\mathrm{H}_{2} \mathrm{O}_{2}$ concentrations above $0.01 \mathrm{M}$. These results agree with those of similar work carried out by Guzman et al. (1999), who attributed the decrease in cyanide concentration to the formation of the cyanate anion $\left(\mathrm{CNO}^{-}\right)$, according to Equation [7]:

$$
\mathrm{CN}^{-}+\mathrm{H}_{2} \mathrm{O}_{2} \rightarrow \mathrm{CNO}^{-}+\mathrm{H}_{2} \mathrm{O}
$$

\section{Effect of iron and copper (free and complexed) on decomposition rate of $\mathrm{H}_{2} \mathrm{O}_{2}$}

Figures $5 \mathrm{a}$ and $5 \mathrm{~b}$ show the effects of iron and copper, respectively, added as sulphate and complexed cyanide salts, on the rate of $\mathrm{H}_{2} \mathrm{O}_{2}$ decomposition. Both the free and complexed cations affected the stability of $\mathrm{H}_{2} \mathrm{O}_{2}$. The rate of

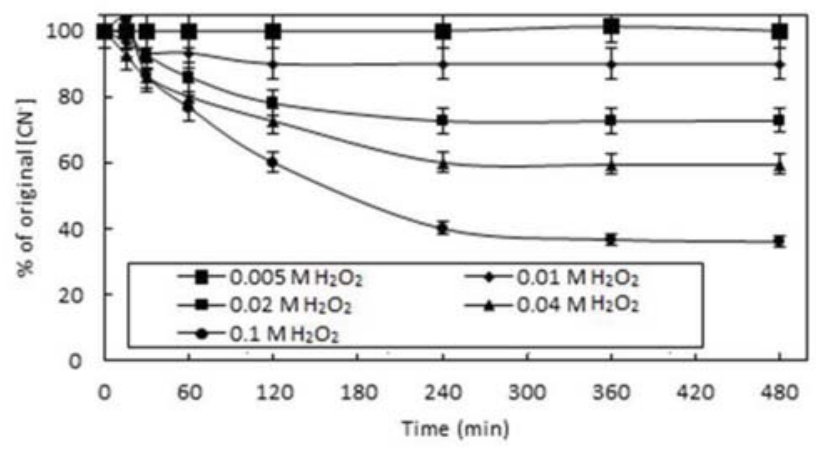

Figure 4-Effect of $\mathrm{H}_{2} \mathrm{O}_{2}$ concentration on the rate of free cyanide destruction. (Initial NaCN: 0.015 M; pH: 10-11.5)

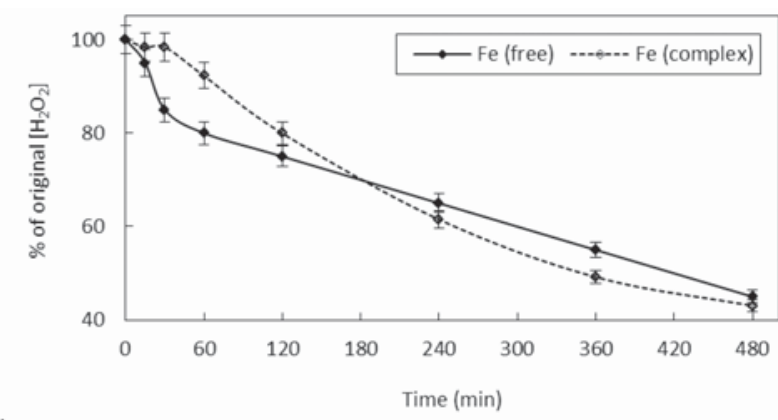

(a)

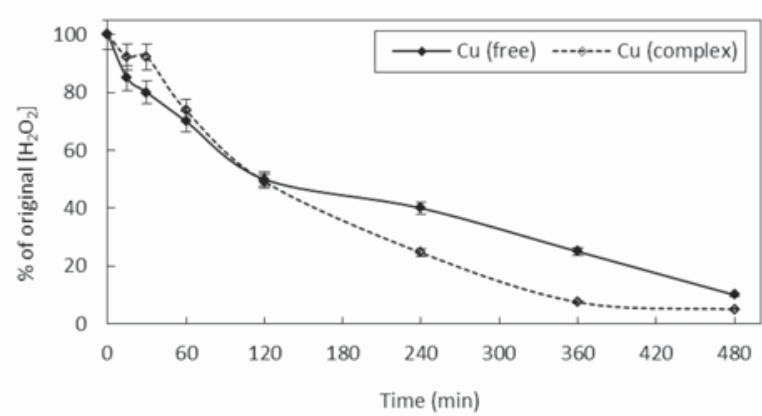

(b)

Figure 5-Effect of free and cyanide complexes of (a) iron and (b) copper on the rate of decomposition of $\mathrm{H}_{2} \mathrm{O}_{2}$ under alkaline conditions. (Initial $\mathrm{H}_{2} \mathrm{O}_{2}$ : $0.01 \mathrm{M}$; $\mathrm{pH} \mathrm{10-11.5;} \mathrm{initial} \mathrm{[M2+],} \mathrm{CuCN}$ or $\mathrm{K}_{4} \mathrm{Fe}(\mathrm{CN})_{6}$ : $0.004 \mathrm{M}$ ) decomposition in the presence of Fe was essentially unaffected by the nature of the ion; copper, however, had a more pronounced effect when present as the cyanide complex. Although copper(II)-cyano complexes have been characterized, they are unstable and decompose rapidly, forming copper(I)-cyano complexes and cyanate, $\mathrm{CNO}^{-}$, in the presence of $\mathrm{H}_{2} \mathrm{O}_{2}$ (Sceresini and Breuer, 2016): the presence of cupric copper (the free $\mathrm{Cu}^{2+}$ ion) therefore causes loss of cyanide as cyanate. These results indicated that $\mathrm{H}_{2} \mathrm{O}_{2}$ decomposed in the presence of iron and copper as both free and complexed species in Fenton and Fenton-like reactions, respectively.

Figure 6 shows the corresponding first-order plots based on the data of Figure 5. The rate constants, $k$, for the decomposition of $\mathrm{H}_{2} \mathrm{O}_{2}$ by these catalysts were calculated from the slope of a linear least-squares fit:

$$
\text { Slope }=\left(\Delta \ln \left[\mathrm{H}_{2} \mathrm{O}_{2}\right]\right) / \Delta t=-k
$$

where the concentration of $\mathrm{H}_{2} \mathrm{O}_{2}$ is given in $\mathrm{M}$.

The equations, rate constants and correlation coefficients $(\mathrm{R} 2)$ for the linear plots are summarized in Table I. The relative values of the rate constants confirm that the rate of decomposition of $\mathrm{H}_{2} \mathrm{O}_{2}$ in the presence of copper was faster than that of iron and that the rates were slightly faster when the metal ions were present in the form of the respective cyanide complexes. The free copper ion reduced the initial $\mathrm{H}_{2} \mathrm{O}_{2}$ concentration by $90 \%$ in 480 minutes, compared with only $55 \%$ in the presence of the free iron species. Similarly, the presence of copper cyanide reduced the $\mathrm{H}_{2} \mathrm{O}_{2}$ concentration by $95 \%$ in 480 minutes, compared with only $50 \%$ for ferrocyanide (Figure 6 ).

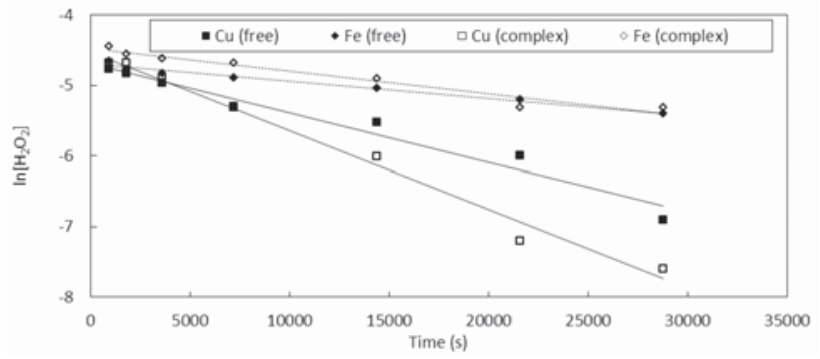

Figure 6-First-order plots for the decomposition of $\mathrm{H}_{2} \mathrm{O}_{2}$ in the presence of $\mathrm{FeSO}_{4}$ and $\mathrm{CuSO}_{4}$ (free cations) and $\mathrm{K}_{4} \mathrm{Fe}(\mathrm{CN})_{6}$ and $\mathrm{CuCN}$ (complexed cations)

Table I

Equations of best linear fit, correlation coefficients and rate constants for the first-order decomposition of $\mathrm{H}_{2} \mathrm{O}_{2}$ in the presence of iron and copper, present as free (sulphate media) or complexed (cyanide media) cations, based on the data in Figure 6

\begin{tabular}{l|c|c|c}
\hline Catalyst & $\begin{array}{c}\text { Regression } \\
\text { equation }\end{array}$ & $\begin{array}{c}\text { Rate constant } \\
\text { (s-1) }\end{array}$ & $\begin{array}{c}\mathbf{R}^{2} \\
\text { value }\end{array}$ \\
\hline Fe (free) & $y=-2.0 \mathrm{E}-05 \mathrm{x}-4.7$ & $2.0 \times 10-5$ & 0.98 \\
Fe (complex) & $y=-3.0 \mathrm{E}-05 \mathrm{x}-4.48$ & $3.0 \times 10-5$ & 0.95 \\
Cu (free) & $y=-7.0 \mathrm{E}-05 \mathrm{x}-4.69$ & $7.0 \times 10-5$ & 0.96 \\
Cu (complex) & $y=-0.0001 \mathrm{x}-4.53$ & $1.0 \times 10-4$ & 0.99 \\
\hline
\end{tabular}




\section{Decomposition of hydrogen peroxide in alkaline cyanide solutions}

\section{Effect of iron and copper cyanide complexes on rate of decomposition of free cyanide in the absence and presence of $\mathrm{H}_{2} \mathrm{O}_{2}$}

Using a $\mathrm{H}_{2} \mathrm{O}_{2}$ concentration of $0.01 \mathrm{M}$, which was shown to have negligible effect on the degradation of free cyanide (supplied as NaCN) (Figure 4), it was of interest to monitor whether cyanide would be similarly destroyed when the catalysts were introduced as the cyano complex ions. Figures $7 \mathrm{a}$ and $7 \mathrm{~b}$ show the decrease in free cyanide with time in the presence and absence of $\mathrm{H}_{2} \mathrm{O}_{2}$ when using iron and copper as the catalysts, respectively. Ferrocyanide is regarded as a strongly bound complex and is therefore not easily dissociated (Adams, 2016; Sharpe, 1976), which is why it tends to remain stable during detoxification of free cyanide and cyanide complexes by $\mathrm{H}_{2} \mathrm{O}_{2}$ (Griffiths et al., 1987; Ozcan et al., 2011). A small decrease in the initial free cyanide concentration was, however, still observed (Figure $7 \mathrm{a}$ ) This was attributed to a Fenton-like reaction between $\mathrm{H}_{2} \mathrm{O}_{2}$ and ferrocyanide, which produces the hydroxyl radical intermediate $\left(\mathrm{OH}^{\circ}\right)$ that, in turn, reacts with free $\mathrm{CN}^{-}$. In the absence of $\mathrm{H}_{2} \mathrm{O}_{2}$, no decrease in the free cyanide concentration occurred for the case of ferrocyanide, confirming the stability of the complex.

For the case of $\mathrm{CuCN}$, the free cyanide concentration dropped markedly both in the presence and absence of $\mathrm{H}_{2} \mathrm{O}_{2}$. It is well-known, however, that copper forms a series of strong cyanide complexes (Ringbom, 1963), of which the triand tetracyanide species predominate at alkaline $\mathrm{pH}$ values (Sceresini and Breuer, 2016):

$$
\begin{aligned}
& \mathrm{Cu}++2 \mathrm{CN}^{-} \rightarrow \mathrm{Cu}\left(\mathrm{CN}_{2}\right)^{-} \quad \log \beta_{2}=24.0 \\
& \mathrm{Cu}++3 \mathrm{CN}^{-} \rightarrow \mathrm{Cu}(\mathrm{CN} 3)^{2-} \log \beta_{3}=28.6 \\
& \mathrm{Cu}++4 \mathrm{CN}^{-} \rightarrow \mathrm{Cu}\left(\mathrm{CN}_{4}\right)^{3-} \log \beta_{4}=30.3
\end{aligned}
$$

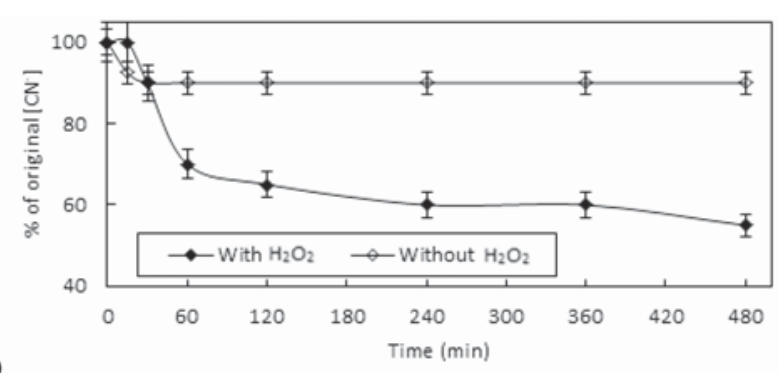

(a)

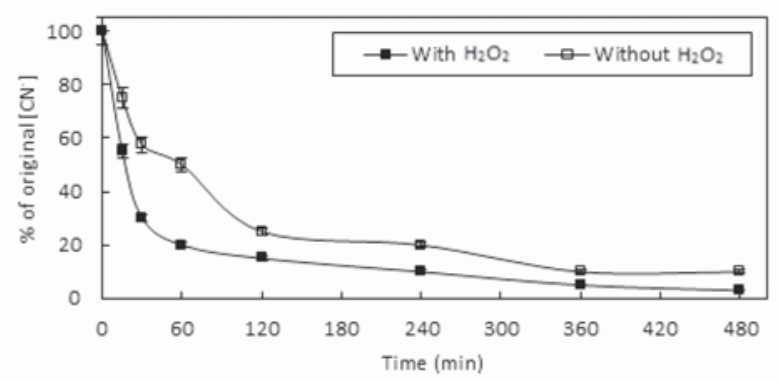

(b)

Figure 7-Effect of (a) iron and (b) copper cyanide complexes on the rate of degradation of free cyanide in the presence and absence of hydrogen peroxide. (Initial $\mathrm{H}_{2} \mathrm{O}_{2}: 0.01 \mathrm{M}$; pH: 10-11.5; initial $\mathrm{NaCN}$ : $0.01 \mathrm{M}$; initial $\mathrm{K}_{4} \mathrm{Fe}(\mathrm{CN})_{6}$ or $\left.\mathrm{CuCN}: 0.004 \mathrm{M}\right)$
Only a slightly greater extent of cyanide destruction occurred in the presence of $\mathrm{H}_{2} \mathrm{O}_{2}$, indicating that this phenomenon is primarily due to complexation, rather than to reaction with the hydroxyl radical due to Fenton-like reactions.

The degradation of free cyanide both with and without $\mathrm{H}_{2} \mathrm{O}_{2}$ occurred according to second-order kinetics in the presence of iron and copper cyanides, as shown in Figure 8, derived from the data presented in Figure 7 . The relative values of the rate constants (Table II), calculated by the equation:

$$
1 /\left[\mathrm{CN}^{-}\right]_{\mathrm{t}}=k \mathrm{t}+1 /\left[\mathrm{CN}^{-}\right]_{0}
$$

where the concentration of $\mathrm{CN}^{-}$was calculated in $\mathrm{g} / \mathrm{L}$, confirmed that copper(I) cyanide caused faster decomposition of $\mathrm{CN}^{-}$than ferrocyanide, both with and without $\mathrm{H}_{2} \mathrm{O}_{2}$.

\section{Radical detection studies}

Salem et al., (2000) proposed $\mathrm{OH}^{\circ}$ as an intermediate product in reactions where the catalyst is a transition-metal complex. In this work, evidence for the existence of the $\mathrm{OH}^{\circ}$ radical in the decomposition of $\mathrm{H}_{2} \mathrm{O}_{2}$ was assumed based on an indirect method (Nguyen et al., 2008). Aromatic hydroxylation of salicylic acid to specifically yield the 2,3- and/or 2,5-DBHA isomers can only occur via the $\mathrm{OH}^{\circ}$ radical (see Equation [5]). The hydroxylation reaction was carried out in the presence of $\mathrm{H}_{2} \mathrm{O}_{2}$ and an iron catalyst under acidic $\mathrm{pH}(2-3)$ and alkaline $\mathrm{pH}(10-11)$ conditions and the reaction products were analyzed.

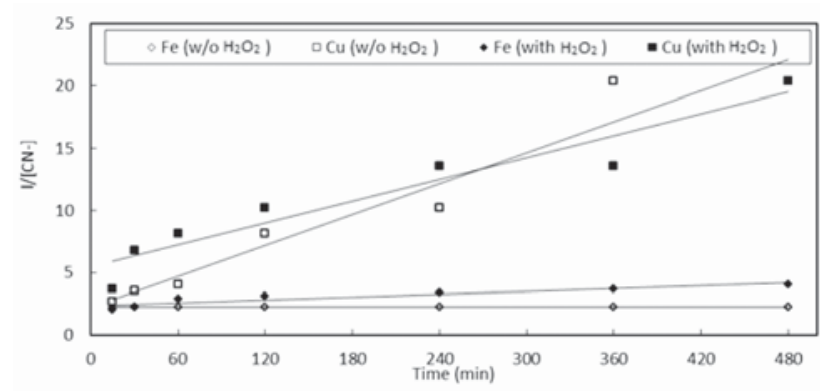

Figure 8-Second-order degradation of free cyanide in the presence of $\mathrm{K}_{4} \mathrm{Fe}(\mathrm{CN})_{6}$ ) and $\mathrm{CuCN}$ in the presence (closed symbols) and absence (open symbols) of $\mathrm{H}_{2} \mathrm{O}_{2}$. (Initial $\mathrm{H}_{2} \mathrm{O}_{2}: 0.01 \mathrm{M}$; $\mathrm{pH}$ : 10-11.5; initial $\mathrm{NaCN}$ : $0.01 \mathrm{M}$; initial $\mathrm{K}_{4} \mathrm{Fe}(\mathrm{CN})_{6}$ or $\left.\mathrm{CuCN}: 0.004 \mathrm{M}\right)$

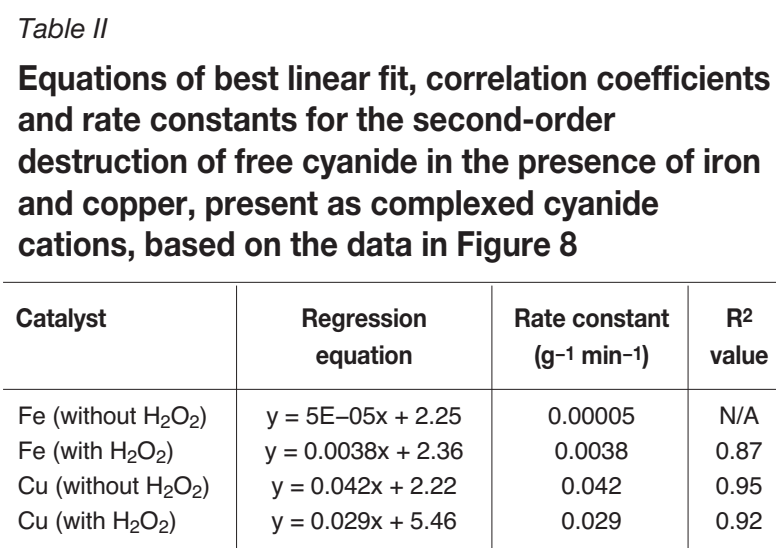




\section{Decomposition of hydrogen peroxide in alkaline cyanide solutions}

NMR spectra of the hydroxylation products compared well with that of the standard 2,3-DHBA isomer (National Institute of Advanced Industrial Science and Technology, 2013): peaks characteristic of the hydrogen atoms of this isomer were observed at chemical shifts of 6.5 to $8.5 \mathrm{ppm}$. IR spectra indicated the presence of carboxylic acid, alcohol, and carbonyl groups, which are the functional groups present in this isomer. Identification of the hydroxylation product of salicylic acid as 2,3-DHBA by NMR and IR spectroscopy, irrespective of whether the reaction was carried out in acidic or alkaline media, indirectly confirmed the presence of $\mathrm{OH}^{\circ}$ and showed that $\mathrm{H}_{2} \mathrm{O}_{2}$ decomposed to this radical under both $\mathrm{pH}$ conditions. It was important to confirm the presence of this intermediate because it is highly reactive (standard reduction potential of $1.4 \mathrm{~V}$ ) compared with the ferryl ion (0.9 V) (Petri et al., 2011) and could possibly react with contaminants in a gold leach pulp, leading to further losses in such application. This high reduction potential of $\mathrm{OH}^{\circ}$ may also improve Au leaching kinetics.

\section{Conclusions}

The aim of this work was to study how the addition of $\mathrm{H}_{2} \mathrm{O}_{2}$ affects the cyanide concentration, the $\mathrm{E}_{\mathrm{h}}$, and the DO concentration in cyanide gold leaching. The effects of transition-metal cation catalysts, such as iron and copper (free and complexed), and pH on the stability of $\mathrm{H}_{2} \mathrm{O}_{2}$ were established. It was found that the cyano complexes of $\mathrm{Fe}(\mathrm{II})$ and $\mathrm{Cu}(\mathrm{I})$ effectively act as hydrogen peroxide decomposition catalysts in alkaline media. Increasing $\mathrm{pH}$ and catalyst concentration increased the rate of decomposition of $\mathrm{H}_{2} \mathrm{O}_{2}$. Copper (free and complexed) cyanide was found to be more effective in decomposing $\mathrm{H}_{2} \mathrm{O}_{2}$ than the corresponding iron(II) species.

It was established that a $\mathrm{H}_{2} \mathrm{O}_{2}$ concentration greater than $0.01 \mathrm{M}$ caused loss of free cyanide. In the presence of copper, loss of free cyanide by complexation was attributed to the formation of stable higher copper(I) cyanide complexes. No loss of cyanide by complexation was observed in the presence of ferrocyanide, in accordance with the known relatively high stability of this complex. Additional losses of cyanide in the presence of hydrogen peroxide were attributed to the presence of the hydroxyl radical in Fenton-like reactions for both iron and copper.

An oxidizing intermediate in the Fenton and Fenton-like reactions, assumed on the basis of detection and identification by an indirect technique to be the hydroxyl radical, was found to be present in both acidic and alkaline solutions. This radical was responsible for the increased oxidation potential observed in alkaline solutions. Proving the presence of this species in alkaline solutions (in the presence of transition metal ion complexes) and understanding its effect on free cyanide degradation could aid in minimizing cyanide losses and establishing economical $\mathrm{H}_{2} \mathrm{O}_{2}$ dosages for industrial applications in gold leaching.

\section{Acknowledgements}

The authors are grateful for financial support from the South African Minerals to Metals Research Institute.

\section{References}

Adams, M.D. (ed.) 2016. Gold Ore Processing. Project Development and Operation. 2nd edn. Elsevier, Oxford.
Arslan, F. Ozdamar, D.Y., and Muduroglu, M. 2003. Cyanidation of Turkish gold-silver ore and the use of hydrogen peroxide. European Journal of Mineral Processing and Environmental Protection, vol. 3, no. 3. pp. 309-315.

Ball, S.P., Monhemius, A.J., and WyboRn, P.J. 1989. The use of inorganic peroxides as accelerators for gold heap leaching. Proceedings of Precious Metals '89. Jha, M.C. and Hill, S.D. (eds.). The Minerals, Metals and Materials Society, Warrendale, PA. pp. 149-164.

BARBUSIŃSKI, K. 2009. Fenton reaction-controversy concerning the chemistry. Ecological Chemistry and Engineering, vol. 16, no. 3. pp. 347-358.

BRAY, W.C. and GoRIN, M.H. 1932. Ferryl ion, a compound of tetravalent iron Journal of the American Chemical Society, vol. 54, no. 5. pp. 2124-2125.

Deguillaume, L., Leriche, M., and Chaumerliac, N. 2005. Impact of radical versus non-radical pathway in the Fenton chemistry on the iron redox cycle in clouds. Chemosphere, vol. 6, no. 5. pp. 718-724.

Fenton, H.J.H. 1894. LXXIII.-Oxidation of tartaric acid in presence of iron. Journal of the Chemical Society, Transactions, vol. 65. pp. 899-910.

GRIFFITHS, A., KNoRRE, H., Gos, S., and Higgins, R. 1987. The detoxification of gold-mill tailings with hydrogen peroxide. Journal of the South African Institute of Mining and Metallurgy, vol. 87, no. 9. pp. 279-283.

Guzman, L., Segarra, M., Chimenos, J.M., Fernandez, M.A., and Espiell, F. 1999 Gold cyanidation using hydrogen peroxide. Hydrometallurgy, vol. 52, no. 1. pp. 21-35.

HABASHI, F. 2016. Gold - an historical introduction. Gold Ore Processing: Project Development and Operations. 2nd edn. Adams, M.D. (ed.). Elsevier, Oxford. pp. 1-24.

HABER, F. and WeISS, J. 1932. Über die katalyse des hydroperoxydes. Naturwissenschaften, vol. 20, no. 51. pp. 948-950.

HABER, F. and WeISS, J. 1934. The catalytic decomposition of hydrogen peroxide by iron salts. Proceedings of the Royal Society of London A: Mathematical, Physical and Engineering Sciences, vol. 147, no. 861. pp. 332-351.

KLASSEN, N.V., Marchington, D., and McGowan, H.C. $1994 . \mathrm{H}_{2} \mathrm{O}_{2}$ determination by the I3-method and by $\mathrm{KMnO}_{4}$ titration. Analytical Chemistry, vol. 66, no. 18. pp. 2921-2925.

KNoRRe, H., Loroesch, J., Gos, S., Stoll, M., and Ziegler, A. 1993. Process for leaching precious metals with hydrogen peroxide and cyanide leaching solution. US patent 5250272 .

KnoRre, H., Griffiths, A., Loroesch, J., and Fischer, J. 1994. Process for the leaching of gold and silver cyanide leaching solution and controlled addition of hydrogen peroxide. US patent 5275791.

LiN, S.S. and GuRoL, M.D. 1998. Catalytic decomposition of hydrogen peroxide on iron oxide: kinetics, mechanism, and implications. Environmental Science and Technology, vol. 32, no. 10. pp. 1417-1423.

LOROESCH, J. 1990. Peroxide-assisted leach: three years of increasing success. Proceedings of the Randol Gold Forum '90. Randol International Ltd., Golden, CO. pp. 215-20.

Mendham, J., Denney, R.C., Barnes, J.D., and Thomas, M. 2000. Titrimetric analysis. Vogel's Textbook of Quantitative Chemical Analysis. 6th edn. Pearson Education Ltd., Harlow, Prentice Hall. pp. 447-449.

National Institute of Advanced Industrial Science and Technology (AIST). Spectral Database for Organic Compounds. Japan. http://sdbs.db.aist.go.jp/sdbs/cgi-bin/cre_index.cgi. [accessed April 2013].

NguYen, V., Bonds, D.V., and ProKAI, L. 2008. Measurement of hydroxyl-radical formation in the rat striatum by in vivo microdialysis and GC-MS. Chromatographia, vol. 68 , no. 1. pp. 57-62.

Nicoll, W.D. and SмIтH, A.F. 1955. Stability of dilute alkaline solutions of hydrogen peroxide. Industrial and Engineering Chemistry, vol. 47, no. 12 pp. 2548-2554.

Ozcan, E., GoK, Z., and YeL, E. 2011. Photo/photochemical oxidation of cyanide and metal-cyanide complexes: ultraviolet A versus ultraviolet $C$. Environmental Technology, vol. 33, no. 16-18. pp. 1913-1925.

Petri, B.G., Watts, R.J., Teel, A.L., Huling, S.G., and Brown, R.A. 2011. Fundamentals of ISCO using hydrogen peroxide. In Situ Chemical Oxidation for Groundwater Remediation. 1st edn. Siegrist, R.L., Crimi, M. and Simpkin, T.J. (eds.). Springer, New York. pp. 33-88.

RingBom, A. 1963. Complexation in Analytical Chemistry. Interscience Publishers, New York.

Salem, I.A., El MaAzAwi, M., and ZaKi, A.B. 2000. Kinetics and mechanisms of decomposition reaction of hydrogen peroxide in presence of metal complexes. International Journal of Chemical Kinetics, vol. 32, no. 11. pp. 643-666.

ScERESINI, B. and BReuer, P. 2016. Copper-gold ores. Gold Ore Processing: Project Development and Operations. 2nd edn. Adams, M.D. (ed.). Elsevier, Oxford. pp. 771-801.

SHARPE, A.G. 1976. Chemistry of Cyano Complexes of the Transition Metals. Academic Press, London.

WANG, X., and ForSSBERG, K.E. 1990. The chemistry of cyanide-metal complexes in relation to hydrometallurgical processes of precious metals. Mineral Processing and Extractive Metallurgy Review, vol. 6. pp. 81-125.

WAtTS, R.J. and TeEL, A.L. 2005. Chemistry of modified Fenton's reagent (catalyzed $\mathrm{H}_{2} \mathrm{O}_{2}$ propagations-CHP) for in situ soil and groundwater remediation. Journal of Environmental Engineering, vol. 131, no. 4. pp. 612-622. 